\title{
Response and associative learning as a function of warmup
}

JOHN C. KOEPPEL, University of Southern Mississippi, Hattiesburg, Miss. 39401 and ALLEN M. RAFFETTO, University of North Dakota, Grand Forks, N.D. 58201

The influence of warmup was investigated in a pairedassociate task in which the learning of responses, as well as the association of stimuli and responses, was measured. $A$ significant warm-up effect was found in the associative stage of the paired-associate task, while no substantial warm-up was observed in the response-learning phase of the same task. The results support Underwood's stage analysis model of paired-associate learning.

In verbal learning a warm-up phenomenon is said to occur when experience with List Al facilitates subsequent performance on a similar list, A2, both lists being learned during the same experimental session. The existence of a powerful warm-up effect in paired-associate learning is well documented. Thune (1950), for example, found that the greater the number of warm-up trials the better the performance on a subsequent list of word stimuli.

The question arises as to where in the learning of a paired-associate task, warm-up is exerting its major influence. Underwood's stage analysis model (1960, pp. 92-94) provides an analytic device for investigating this question. In this framework the paired-associate task is composed of two processes: (1) a response-learning phase in which responses are learned as such; and (2) an associative stage in which the appropriate stimulus is hooked up to the correct response.

There is evidence that the familiar warm-up effect does not generally appear in free recall, a situation which seemingly involves a great deal of response-learning. Murdock (1960) using familiar words as stimuli failed to obtain significant warm-up in a series of free-recall experiments. Raffetto \& Koeppel (in press) failed to observe warm-up effects when either conceptually related or unrelated words served as stimuli for free recall. If the response-learning phase of paired-associate learning can be equated with free recall, then it may be predicted that warm-up will not exert a significant influence upon the response learning phase of the task. Any substantial effect of warming up will be localized in the associative stage of the paired-associate task.

\section{METHOD}

Two paired-associate lists were constructed; each list contained nine pairs of unrelated, two-syllable nouns selected from the Thorndike-Lorge (1944) list to have an average G frequency value of one. The items in the two lists were low in conceptual similarity both within each stimulus-response (S-R) pair and among all S-R terms in a given list. In fact, no concept was represented in a list more than once, and an effort was made so that concepts used in the first list would not appear in the second. The items were mounted on slides and shown to Ss by means of a Kodak Carousel 800 Projector. The stimulus materials were presented on alternate study and recall trials. On study trials the S-R pairs were successively presented and Ss were instructed to learn the items during this period. After every study trial a recall trial occurred, during which Ss were to indicate how much they had learned. The recall trials were so arranged that on half the trials Ss were presented with the stimulus items alone and were required to give the response item which was paired with each stimulus on study trials. On the other half of the recall trials Ss were not presented with any stimuli; instead, Ss were told to recall all the response items in any order. These two methods of recall provided measures of associative and response learning, respectively. The recall trials were so arranged that every other trial was a measure of response learning. The Ss went through four associative trials and four response-learning trials. Then a second list was presented to the same Ss and four more associative- and response-learning trials were given. The slides were presented at a 4-sec rate with one additional second elapsing between the presentation of successive slides. Three different orders were used to minimize possible serial-learning effects. Each $S$ recorded his responses in a booklet which was arranged so that previous responses were not visible.

The Ss were 22 students, 10 males and 12 females, enrolled in introductory psychology classes at the University of North Dakota. The investigation was a replication of an earlier pilot study which yielded closely comparable results.

\section{RESULTS AND DISCUSSION}

A significant warm-up effect appeared in the associative stage of the task, but performance in the response learning phase was not substantially altered. Performance over four trials is shown for both stages of learning in Fig. 1. The data for the associative stage revealed a highly significant difference between lists $(F=8.60, d f=1 / 21, p<.01)$. The curves for associative learning are nearly parallel over all trials, with associative performance on List 2 consistently superior to associative performance on List 1 . Use of the Newman-Keuls technique revealed differences on the associative trials significant for Trials 1 and $2(p<.01)$. A trend in the expected direction was found for Trials 3 and 4 . In contrast. there were no significant differences between lists for response learning $(F<1.0)$. In fact, as Fig. 1 illustrates, the performance of Ss in the response phase was almost indistinguishable for the two lists.

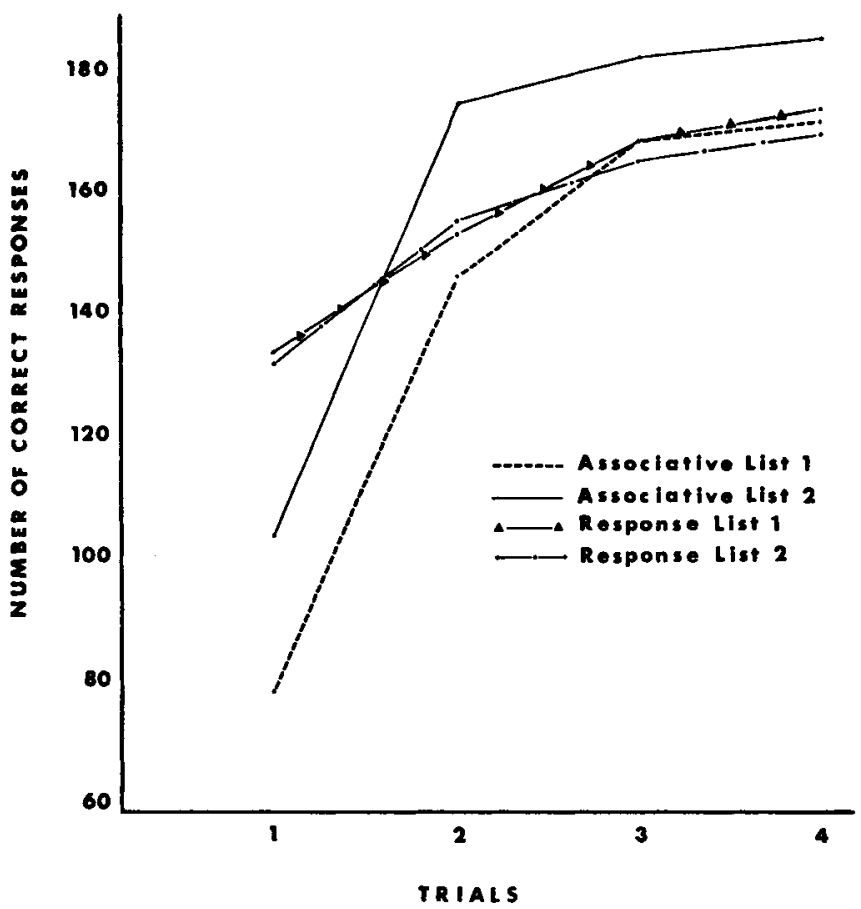

Fig. 1. Response and associative learning as a function of trials. 
difference between means was not significant $(t=.90$. $\mathrm{df}=162$ ), indicating no significant superiority of the forward conditioning groups.

Mean differential conditioning scores were also computed for those Ss who reported no awareness of the relationship between the letters $Q$ and $X$ and the types of words paired with them. The numbers of nonaware Ss were 24, 17, 24, and 21 for Groups B2, B1, F1, and F2, respectively. A $x^{2}$ test showed that the numbers of Ss showing awareness in the four groups did not differ significantly from values expected by chance. The mean differential conditioning scores were .27 for Group B2, -.43 for B1, .24 for F1, and 1.10 for F2. The only mean significantly greater than zero was that of the $F 2$ group $(t=4.4, d f=20, p<.01)$.

\section{DISCUSSION}

The results showed (1) that all groups, forward and backward, exhibited differential conditioning significantly greater than zero, (2) that there were no significant differences among the differential conditioning means for the four ISI groups, (3) that the difference between forward and backward treatment groups was not significant, and (4) that the conditioning effect tended to disappear when aware Ss were excluded. These results are not consistent with those found for most classically conditioned responses. Backward procedures usually produce no conditioning, and ISIs of greater than $1 \mathrm{sec}$ usually produce minimal conditioning. More important, the ISI condition in the present experiment which was most similar to the optimal ISI for classical conditioning, i.e.. Fl, did not lead to the greatest degree of differential conditioning.

The major conclusion to be drawn from the results is that the ISI function for conditioned word meaning does not resemble the function observed for classically conditioned responses such as the GSR, the eyeblink, and flexion responses. If one demands that a response behave as other classically conditioned responses when powerful variables such as ISI are manipulated in order to be classified as a classically conditioned response, then conditioned word meaning fails to meet the test. It has not been demonstrated that variables affecting classically conditioned responses in characteristic ways affect conditioned word meaning in similar ways, excepting the effects of variables such as percentage of reinforcement and number of trials, which affect almost all learned responses, classically conditioned or not, in similar ways. In short, the characteristic functions relating level of classical conditioning to kevels of independent variables have not been shown to exist for word meaning responses.

That word meaning is not classically conditioned is also indicated in the present study by the fact that the conditioning was due almost entirely to the scores of Ss who were aware of the relation between the letters and the word classes used. Only for Group F? was the degree of conditioning significantly different from zero when aware Ss were eliminated. This finding replicates that of other recent investigations (Cohen, 1964: Hare. 1964: Insko \& Oakes, 1966: Pavio, 1964) and is a further indication that the learning process is probably not classical conditioning. Classical CRs are generally defined as nonvoluntary responses, but word meaning responses appear to occur only when $S$ is aware of the relation between CS material and US material.

On two counts, then. the labeling of word meaning responses as classically conditioned responses appears unjustified. First, in contrast to classically conditioned responses, the acquisition of word meaning does not depend on the ISI used and has not been shown to be related to other independent variables in ways similar to classical CRs. Second, in contrast to classically conditioned responses the occurrence of conditioned word meaning responses depends on S's awareness of the relation between CS letters and US words.

\section{REFERENCES}

BEECROFT, R. S. Classical Conditioning. Goleta, Calitornia: Psychonomic Press, 1966.

COHEN, B. H. Role of awareness in meaning established by classicil conditioning. Journal of Experimental Psychology, 1964, 67, 373-37\%.

GERSTEIN, A. I. The effect of reinforcement schedules on meaning generalization and on awareness of the purpose of the experiment. Journal of Personality, 1961, 29, 350-362.

HARE, R. D. Cognitive factors in transfer of meaning. Psychological Reports, 1964, 15, 199-206.

INSKO, C. A., \& OAKES, W. F. Awareness and the conditioning of attitudes. Journal of Personality, 1966, 4, 487-496.

PAVIO, A. Generalization of verbally conditioned meaning from symbol to referent. Canadian Journal of Psychology, 1964, 18, 146-155.

STAATS, C., \& STAATS, A. W. Meaning established by classical conditioning. Journal of Experimental Psychology, 1957, 54. 74-80.

STAATS, A. W., STAATS, C., \& HEARD, W. G. Language conditioning of meaning to meaning using a semantic generalization paradigm. Journal of Experimental Psychology, 1959, 57, 187-191.

STAATS, A. W., STAATS, C., \& HEARD, W. G. Attitude development and ratio of reinforcement. Sociometry, 1960, 23, 338-350. NOTES

1. This investigation was supported, in part, by a Faculty Research Award from the University of North Dakota to the second author.

2. Now at the University of Mississippi.

\section{(Contintued from page 59)}

The results are quite clear: For word stimuli there are warm-up effects in the associative stage of paired-associate learning but not in the response-learning stage of the same task. This suggests that the finding of previous investigators which indicates the presence of a warm-up effect in paired-associate learning may be largely attributed to the warming up that occurs in the associative stage of that task. It appears that warm-up effects are largely localized in the associative stage of paired-associate learning.

The similarity between performance on response learning in the current experiment and free recall of unrelated words in the Raffetto \& Koeppel study (1968) is quite striking. In both cases no significant increase could be found in performance from list to list, yet in both experiments improvement over trials occurred within lists. This close resemblance of findings supports the assumption that the processes which are operative in the response-learning phase of paired-associate tasks roughly correspond to the processes involved in free recall.

\section{REFERENCES}

MURDOCK, B. B., JR. The immediate retention of unrelated words. Journal of Experimental Psychology, 1960, 60, 222-234.

RAFFETTO, A. M., \& KOEPPEL, J. C. Warmup effects in free recall. Psychonomic Science, 1968, 12, 397-398.

THORNDIKE, E. L., \& LORGE, 1. The teacher's word book of 30,000 words. New York: Teacher's College, Columbia University, 1944.

THUNE, L. E. The effect of different types of preliminary activities on subsequent learning of paired-associate material. Journal of Experimental Psychology, 1950, 40, 423-438.

UNDERWOOD, B. J., \& SCHULZ, R. W. Meaningfulness and t'erbal learning. Philadelphia: Lippincott. 1960. 